\title{
The Social Equality of Children with Special Needs in Mataram
}

\author{
${ }^{1}$ Astrit Maria \\ ${ }^{1}$ Mataram University, Mataram, Indonesia \\ astritmaria@outlook.com
}

\begin{tabular}{|c|c|}
\hline Article Info & Abstract \\
\hline $\begin{array}{l}\text { Article History } \\
\text { Received: July 12, } 2018 \\
\text { Accepted: September 30, } \\
2018 \\
\text { Keywords } \\
\text { Social Equality; Peace and } \\
\text { Justice; Quality Education; } \\
\text { Social and Education; } \\
\text { Special Needs Children }\end{array}$ & $\begin{array}{l}\text { While disability is treated socially equal in most western countries, the } \\
\text { prejudice that Asians adhere to traditional cultural view related to curse, } \\
\text { bad luck, and humiliation is really strong. In fact, attitudes toward the } \\
\text { handicapped strongly refer to social as well as cultural construction built in } \\
\text { society. Hence, this research was conducted to discover how Mataram } \\
\text { natives truly treat child with special education needs in the social } \\
\text { interactions within school setting using qualitative approach and engaging } \\
\text { observation as well as video recordings as data collection methods. The } \\
\text { findings confirm that destructive treatment does not occur among Mataram } \\
\text { disabled and non-disabled peers despite the existing prejudice. Moreover, } \\
\text { constructive treatment from the community builds the child's self-esteem in } \\
\text { public setting stronger. }\end{array}$ \\
\hline $\begin{array}{l}\text { Support by: } \\
\text { do) Crossref }\end{array}$ & his is an open access article under the CC-BY-SA license \\
\hline
\end{tabular}

\section{INTRODUCTION}

Hundred years before, people with disability were perceived as sin, curse, as well as terrible disease (Abosi and Ozoji, 1985). They were not handled properly that many encountered exile, isolation, and even proscription (Franzen Bjorn, 1990). In the nowadays life, disability is no longer perceived as incurable impropriety. Large numbers of social awareness movements have contributed to creating more peaceful world. They have changed the way people handle others and how society starts accepting their presence. There is less exclusion to people with disability. Besides, there is growing opportunity for them in various life aspects. The changing perspectives by society does not only change communal behavior, but also how the government embraces disability by providing better social, health care, community living, employment, as well as educational treatment (Lopez, 2013).

Once the awareness is spread out among communities, there emerge better public attitudes upon the handicapped (Lynch and Hanson, 2004). As what occurs in the most Caucasian countries, people with special needs are treated equally as they view disability by means of uniqueness and literally needing special attention. Hence, countries as well as citizens hand more concern towards the special needs groups.

On the other hand, in many Asian countries, the prejudice that its cultural value of disability remains to see it as curse or violation against cultural ties grows strong, in spite of the fact that social dissemination of disability has widely spread out and start transforming community's attitude in the most developed countries. For instance, it is culturally believed that mothers in China who previously did something wrong or against the cultural belief when pregnant will have sick children as punishment. The blame can also go on the family. If the family harms the other family, it is believed that having disabled family member is what they get in return. Seeing this, the explanation 
above leaves us with the conclusion that how culture sees disability will definitely manage to predispose what behavior the society offers.

This depressed fact occurring in Asian countries has been indeed alarming that the researcher was disposed for figuring out if there is any inadequate social way of treating people with special needs in Indonesia, one of countries in Asia. Besides, Indonesia is a country where tourism attractions are everywhere. Specifically in Lombok, one of west islands in Indonesia, this prejudice becomes an issue that threatens future tourism domain for this image. Hence, this study engaged one of schools in Mataram, to evidently figure out if this image exists in the educational domain in Mataram, where people across the world come over to for vacation as well as social experience.

\section{Disabilities}

In general, disability includes any loss, impairment, as well as anomalies psychologically or physically causing its structure and/or its function to perform in a manner beyond or less than what other human beings can normally do (Disability Action Council, no date; Bingham et al, 2012).Additionally, Hassanein (2015) claimed that disability appears to people living in special condition which their mental and physical variety happen to be weak or not able to work as what is expected. As the instance, humans are commonly gifted with two hands and two legs. As one individual appears to own one left hand interfering his ability to write and perform activities in normal condition, this person is perceived as special need member in terms of physical condition. It goes the same when an individual finds it hard to focus on group study. The only situation he fits in is when studying alone with the tutor as he loses attention so easily. Regarding this, the person is categorized as special need member in terms of mental disorder.

Primarily, the types of special needs condition are two; physical and mental health. In physical, people are suffered with mobility impairment, brain disability due to injury or disease, vision impairment, hearing loss, as well as speech impairment. Meanwhile in mental health, individual is afflicted in psychological disorder (personality, mood, disturbance of behavior, and thinking disruption), learning disability, intellectual disability, and autism spectrum disorder.

As the number of children born with anomalies rises higher, more studies examined aspects which are the significant drivers of abnormalities in people. Disability Action Council (no date) clarified a number of possible factors driving one individual to hold or to develop disability (https://www.and.org.au/pages/disability-statistics.html). Firstly, physical defects since birth, or most-known as 'genetic disorders', may naturally interrupt one's performance compared to normal born children. Being born with physical impairment, such as, hearing, speaking, or walking, surely prevent the disabled from growing up common. The one suffering such impairment obviously requires special help both medically and socially. Secondly, children receiving special need condition inherited from parental genetic heredity has been proven medically. As one parent holds disorder, this condition may inherit to the children given birth as well. As the example, Lopez (2013) explained that autism spectrum disorder may retain from parental genetic syndrome dominating the children's medical condition. Thirdly, riskily injured accident can lead to either physical impairment or mental trauma, or even both. Some of these significant impacts are curable medically yet great support during recovery is required. Fourthly, either an extreme injure or distressing experience in the past can lead an individual to suffer from trauma. Furthermore, the unhandled trauma in children with mental abnormalities receiving less support or even none from community as well as family members grow psychological disorder worsened. 
While medical check is essential, the absence of supports in other aspects will bring the handicapped nowhere. As a consequence, there are some other significant supports urgently needed. First, other than health, social support is worth mentioning. Receiving medical support while getting no acceptance from surroundings is high and dry because the sufferer's feelings also matter. The second help needed will be from educational sphere. Skrtic (1991), Kagan (1992), Forlin et al, (1996), Barton (1997), and Carrington (1999) argued the school that special needs students study in must provide different school culture offering educational reform, teacher's behavior upon them, teacher's understanding as well as competence to make available any appropriate learning they need, school acceptance, inclusive culture, increasing progress, and good communication among teachers and parents. As a result, principally in any domain, social's acceptance and constructive treatment contribute to the success of disabled persons' handling. They are basically part of society members, thus, they confidently need the social involvement.

\section{Social model of disability}

Some countries adhere to the five Social Model of Disability (Oliver, 1983); cultural, charitable, religious, medical, and social model. Firstly, cultural model strongly refers to cultural perspectives upon a certain case and how to cope with it. Luckily, while Latinos do believe in its cultural view upon this that define disability as a curse from Above and must be handled spiritually, Native Americans do believe culturally that handicapped people are message from the supernatural world and human is obligatory to treat them with high respect. Moreover, the only way to cure it is to ask help from the scholars (Nichols and Keltner, 2005). This clearly appears that cultural view puts impact on how society works. Secondly, charitable model deals with one's misfortune and that he deserves to be pitied. Since awareness and financial status in the West are more stable than in Asia, there exist more charity act and community contribution to help make a better place for disabled people (Munyi, 2012).

The third, the religious model, one disability is seen as God's special message to be high valued. Baker et al. (1953) argued that Christian philosophy in the past time saw handicapped persons as a means of state of grace or sin purification. On the subject of this, Christian assumed that human impairment is the manifestation of God's miracle. As Christian's belief upon the sick is encouraging, so is Islam's. Clearly written in the Holy Qur'an (2:282), such afflicted condition by way of mental as well as physical does exist. Nevertheless in the Holy Qur'an (22: 46) explains that what put human in danger is not the physical blind nor the physical deaf, yet it is the blind of heart and the deaf of heart from seeing spiritual and ethical truth (Hassanein, 2015). Fourthly, medical model sees special needs people by the disease someone unfortunately has and it is curable using modern innovations and psychological support. As Americans do have faith in modern medical help both in terms of physical as well as mental care, many obtain proper health care and services that are generally well-accomplished in the West (Lippman, 1972; Wright 1973). Lastly, social model is the strongest model that the cultural view has impact on. As one culture sees disability in a more positive way, it will go along with the social treatment as well. Especially in the western countries, plenty of communities do not decline the presence of disability in society, thus, the social model shows salutary attitude upon them. Such unpleasant diversification less happens. In brief, four out of five models enormously rely on how the culture beholds special needs condition that put its society to perform a certain behavior in regard to its cultural faith.

Social equity

Many have claimed objections that the communities in the country, where they were born and grow old, override the special need persons. Thus, there has been injustice of 
the way they are treated in society causing them to acquire less opportunity to develop socially, financially, mentally, and ethically (Biddix et al., no date; p. 2-4). Then, social justice was mainly proposed by the New Public Administration concerning the social equity movement. Previously, John Stuart Mill also projected to freedom to human diversity. In addition, John Rawls showed up with his "A Theory of Justice" promoting the whole society welfare. To create a more equitable civilization, there should be nobody left behind (http://www.policylibrary.com/rawls/).

Chiefly in the US, the whole citizen must obtain equal opportunity to education as they believe education is the strongest way to create a better prosperous life. President Bush has previously mentioned "When it comes to the education of our children... failure is not an option." (Biddix et al., no date; p. 4).The Amendments of 1997 by the Individuals with Disabilities Education Act (IDEA) in 1997 (Public law 105-17) by President George W. Bush contribute a stronger promotion towards disabled people equity. The USA government has established that the entire individual or groups regardless of their condition; disabled or non-disabled, deserve equal social treatment, educational opportunity, and other life necessities.

\section{Model of destination image}

There are mainly a number of influencing determinants that are significant on the image of tourism attraction destinations. Some of which are the image management through the social, cultural, and political movement (Baloglu and McCleary, 1999; Su, et al, 2018). Social movement can be done by exposing appealing social characters of the tourism destinations. This appealing character also contributes to the better promotion of the place. Moreover, the richness of cultural value also plays a big role in creating image of the place. For example, the existence of various religious practices, ancient sculptures, and many others. Last but not least, the political condition of the country also determines the image of the tourism destinations. Not only its condition, but also political regulations maintain sustainable development of the tourist attractions.

\section{METHOD}

This study employed qualitative approach by interpreting elements, purpose as well as truth of conditional realities and claims as the means to explain any occurrence existed (Harwell, 2011). This research approach aims to essentially expose various implications within phenomenon for its uniqueness.

In discovering reality happening in communities, this mini research appears to scientifically verify that group diversity does exist in daily lives. The aims are to witness how the community performs attitude of social interaction to the special needs people and whether they acquire equitable manners from others. Moreover, this research is eager to grasp how such particular manners towards disabled people influence their way of making societal contacts in a tourism society. Particularly in Mataram, none has described the communal contact among disabled and non-disabled groups.

This research engaged the convenience sampling of the non-probability sampling. The biggest determinant was because the researcher was a part of the selected community, a private middle school in Mataram. In the community, the observer was the teacher of the child with special needs, a fourteen year old boy suffering from Autism Spectrum Disorder. Since the researcher performed as the child's teacher, not a stranger, the condition being observed was normal condition, it was not manipulated that could tell the genuine circumstances of the student and his classmates. For that reason, the researcher concerned on this autistic disorder child to seek if the peers welcome him. 


\section{RESULTS}

Having observations and video recordings, it is evident that everyone accepts the autistic boy's existence and gets along with him. He plays, joins lessons, and communicates with others as he is no difference from them. His mental disorder does never prevent classmates to make friends with him. In games, others also treat them like the other regular peers. The peers do neither necessarily cheat on him nor exclude him away. When having lessons in class, he is surely assisted by a shadow teacher to help him stay focus and comprehend the material step by step. Even so, the classroom teacher may give him the same level of lessons with others, yet less in quantity. Moreover, the classmates show some respect to the autistic boy when he has the chance to go in front of the class answering questions and even presenting his work.

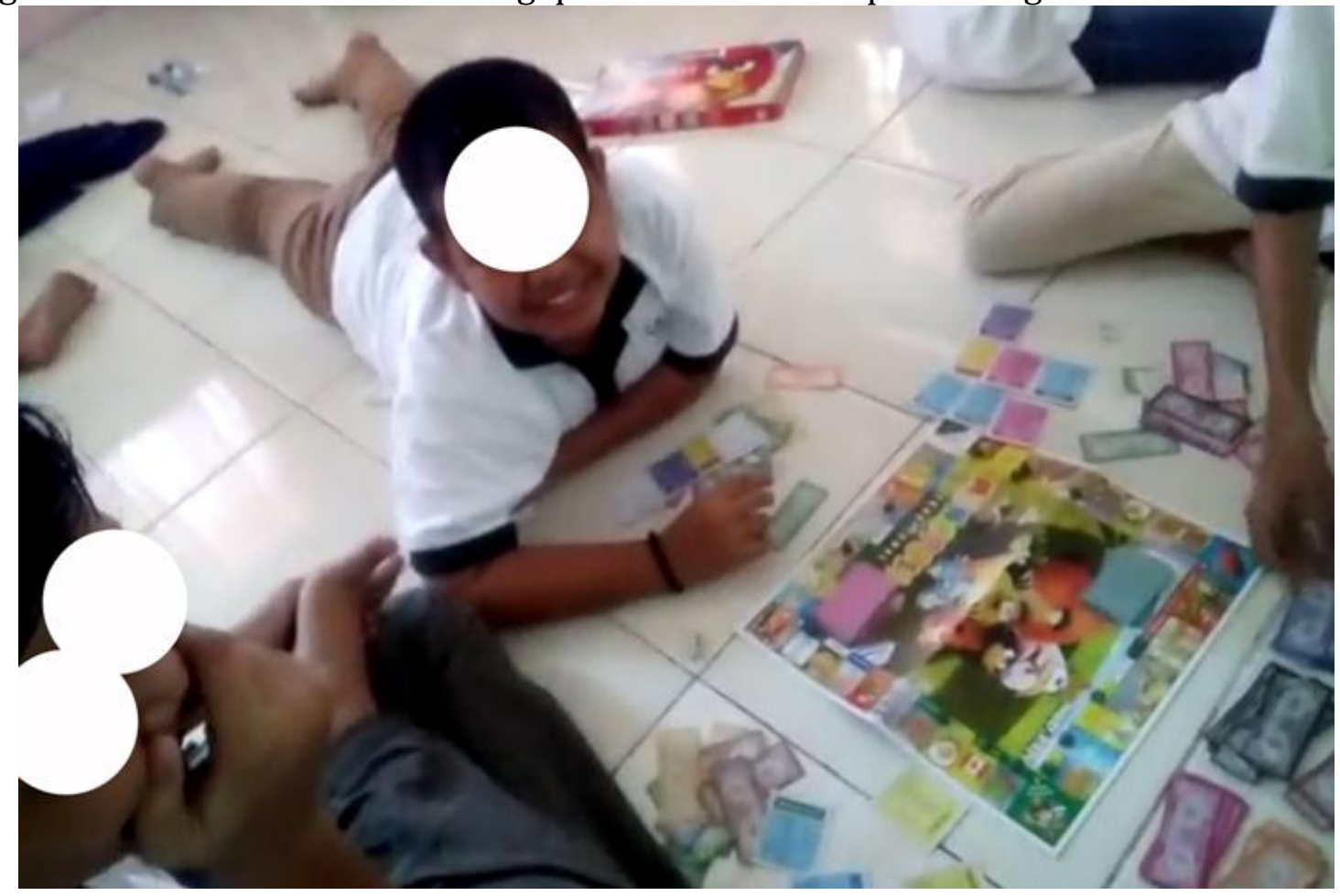

Figure 4.1. The autistic student is playing monopoly board game.

In regard to the video interpretation, the boy suffering from autism was playing some games; Monopoly (figure 1) and Uno Stacko (the block-stacking tower game; appendix 3). In the monopoly game, it clearly displays the happy face of the boy for playing the game (figure 4.1). He enjoys playing the game and the friends are very serious as well as motivated during the game. The mates enjoy playing with the boy with autism; they have no gap towards him.

In the Uno Stackogame, it can be inferred that the autistic boy contributes to the tower building with his two peers (figure 2). His friends do not mind having him in the game and even give him chance to take part. Hence, they build the stacking tower together that they can play after structuring it. The boy seems to participate actively in the game. He does not give the impression to feel small among his friends. 


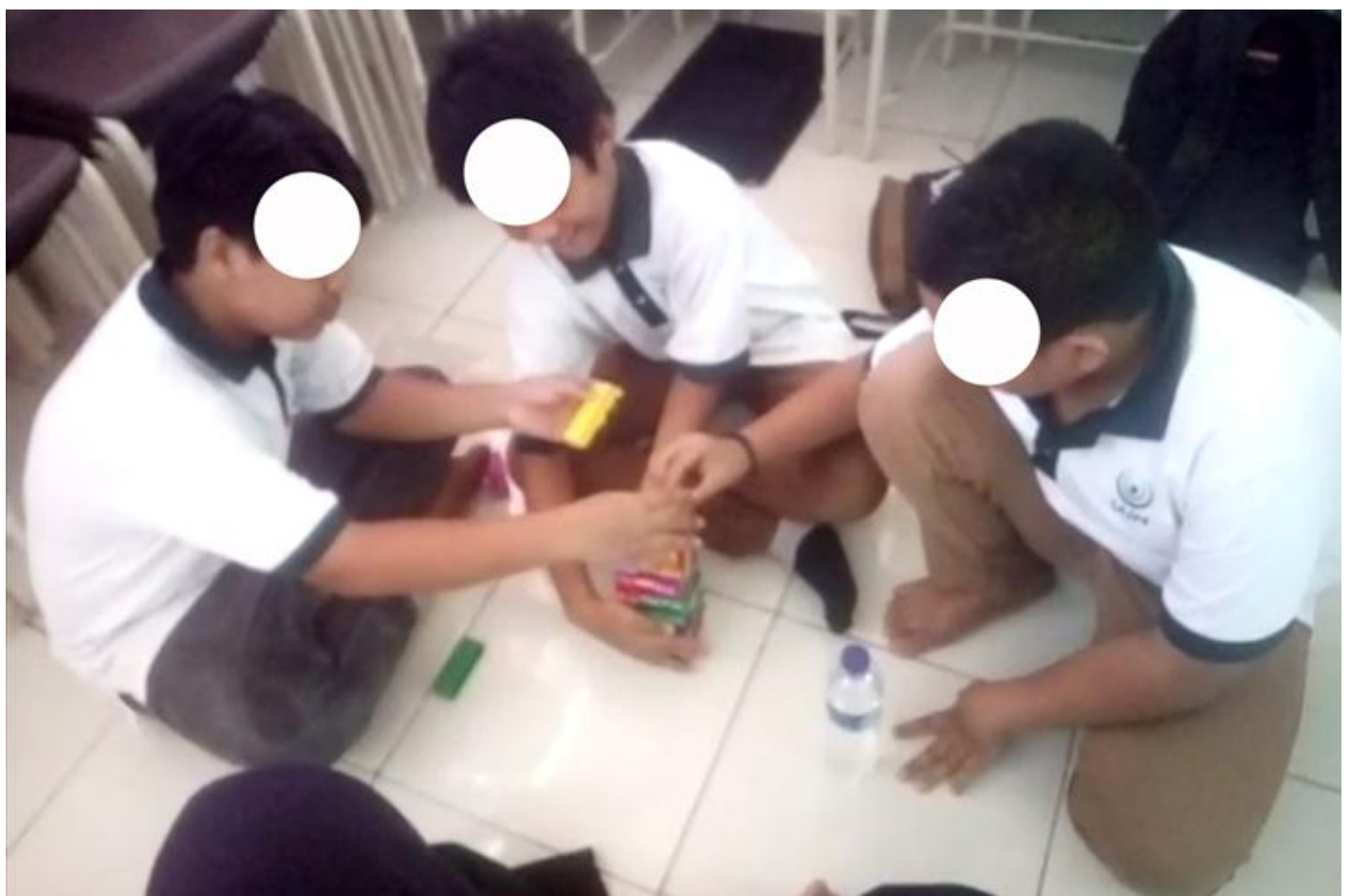

Figure 4.2. The autistic student is playing Uno-Stacko tower game 1.

Those situations are only a piece of how pleasant the friends treat the autistic boy. His psychological weakness is disregarded when they socially interact. Even the peer does not mind helping him build the tower. The findings of this study have made a salutary perspective that social treatment among private middle school students in Mataram is welcoming to the autistic boy. There is no such rejection, hatred, or even revulsion.

It can be inferred from the findings beforehand that positive attitude exists in the social interaction treatment among the autistic boy and his peers. The peers do not show any revulsion, isolation, nor hate to him. They kindly treat the boy with care and help. It was previously discussed that such positive attitudes only happen in western countries and Asian countries does not provide any positive attitudes due to its faith upon traditional culture. These findings provide evidence scientifically that pleasant interaction treatment to the student with special needs do exist among Mataram communities. In addition, the boy with Autism Spectrum Disorder does receive social equity as he gets equal socio-interaction opportunity like others (Shafritz and Russell, 2000; Stone, 2002). Not only socio-communication, but also he acquires good educational acceptance from the surroundings.

It is believed when the cultural model welcomes the presence of person with special need, the other models will follow (Haihambo and Lightfoot, 2010).Mataram natives do not adhere to conventional belief that being handicapped is a shame, curse, bad luck, and many other prejudices. Accordingly, Mataram people hold no intention to perform such behavior to the deformed. For example, when the society does not put the special need boy away, other needs are no longer an issue to the student with disabilities. Plenty of opportunities are opened for the student as well. The friends are glad to help him play the game and do not mind having him involved; charitable model (figure 4.2). He acquires educational chance where he studies in the same way as the others; social model. Besides, psychological support from friends in daily interaction indicates that the medical model exists.

Other than cultural model reason, the contributing factor why the peers express their welcome towards the person is that the social disability awareness has broadly 
spread out in most areas in Mataram. The citizens do not reject disabled people away in these modern days. In this era, the more people undervalue others, the smaller their social image will become (Eelen, 2001; Watts, 2003). This is because only people with such narrow-minded valuing others based on one's physical appearance or mental health (Felix-Brasdefer, 2008). Rather, greater numbers of people come to an understanding that the way one individual treats others reflects on his beauty of heart (Bargiella-Chiappini, 2003). More people appear to encourage kindness to be more essential in life. One of the spreading-kindness manifestations is the occurrence of social equity for all group levels, either high or low class, young or old, commonly normal condition or impaired the tall or the short, the fat or the thin, the white and the dark. This proves that real-life social interaction in the communities with disabilities plays bigger role than such prejudice saying that Asians are narrow minded by treating the defects unpleasantly.

Furthermore, it is proven that the student with autism's interactions in public setting experience no difficulty. He receives no distinctive social interaction from the peers. The boy's confidence appears to grow better as well whenever communicating with friends. He enjoys doing things with peers and does not feel pessimistic regardless of his flaw. The discussion leaves us with conclusion that treatment among peers in public settings inspires special need child to be way more motivated as well as enthusiast in communication. What is more, the social performance of the special developmental student needs to be saluted as his confidence appears strong in a good way.

This result of investigation leads us to the notion that the social interaction in Lombok, Indonesia, confirms an appealingly friendly society for anyone visiting or staying in. As the social treatment to the special developmental child is satisfactory, this paper is confident to claim that this friendly and tolerant character is within Lombok people. Consequently, Lombok is one of tourism attractions in Indonesia that can be put into the traveling-wish-list from people across the world.

\section{SIMPULAN}

Given this clear description of how educational domain in Mataram performs a welcoming social interaction even to the disabled students, it can be inferred that Lombok, as one of big tourist attractions in Indonesia, manages to be the safe, attractive, as well as welcoming destination for people across the world by claiming no judgment to any tourists coming and bringing varied backgrounds as well as experiences. As children mainly grow up to school settings and it impacts on their personal view towards society, this result indicates that the future tourism domain in Lombok is getting friendlier and more open to the world providing the international sustainable halal tourism destinations and services.

\section{REFERENCE}

[1] Abosi, C. O., \&Ozoji, E. D. (1985). Educating the blind: A descriptive approach. Ibadan: Spectrum Books.

[2] Amoako, J.B. (1975). Division of Rehabilitation Status Report. Accra Ghana Ministry of Labour, Social Welfare, and Community.

[3] Baloglu, S. \&McCleary, K. W. (1999). A Model of Destination Image Formation. Annals of Tourism Research, 26(4), 868-897.

[4] Bargiela-Chiappini, F. (2003). Face and politeness: New (insights) for old (concepts). Journal of Pragmatics, 35, 1453-1469. 
[5] Barker, R. G., (1953). Social Sciences Resource Council, Wright, B.A., Meyerson, L., \&Gonick, M.R. Adjustment to physical handicap and illness: A survey of the social psychology of physique and disability. New York.

[6] Barton, L. (1997) Inclusive education: romantic, subversive or realistic? International Journal of Inclusive Education, 1, 231-242.

[7] Carrington, S (1999) Inclusion needs a different school culture. International Journal of Inclusive Education, 3(3):257-268.

[8] Cohen, L., Manion, L., \& Morrison, K. (2007). Research methods in education (6th ed.). London: Routledge.

[9] DeLouisa, S. (no date). Views of Varying Cultures on Students with Special Needs. State University of New York.

[10] Disability Action Council, Cambodia. (No date). CHILDREN WITH SPECIAL NEEDS IN THE CLASSROOM.

[11] Eelen, G. (2001). A critique of politeness theories. Manchester: St. Jerome Publishing.

[12] Forlin C. (1995). Educators beliefs about inclusive practices in Western Australia. British journal on special education, 22, 179-185.

[13] Forlin, C. (1997). Inclusive education in Australia. Special Education Perspectives, 6(1), 21-26.

[14] Forlin, C., Douglas, G. and Hattie, J. (1996) Inclusive practices: how accepting are teachers? International Journal of Disability, 43, 119-133.

[15] Franzen, B. (1990). Attitudes towards people with disabilities in Kenya and Zimbabwe.

[16] Gass, S. M., and Mackey, A. (2012). Data Elicitation for Second and Foreign Language Research. Mahwah: Routledge.

[17] Goldenberg \& Plato. (1974). A word for exceptional children.

[18] Haihambo, C., and Lightfoot, E. (2010). CULTURAL BELIEFS REGARDING PEOPLE WITH DISABILITIES IN NAMIBIA: IMPLICATIONS FOR THE INCLUSION OF PEOPLE WITH DISABILITIES. International Journal of Special Education, 25(3), 76-87.

[19] Harwell, M.R. Research design: Qualitative, quantitative, and mixed methods. (2011). In C. Conrad \& R.C. Serlin (Eds.), The Sage handbook for research in education: Pursuing ideas as the keystone of exemplary inquiry (Second Edition). Thousand Oaks, CA: Sage.

[20] Hassanein, E. E. A. (2015). Inclusion, Disability and Culture. Rotterdam: Sense Publishers.

[21] http://www.policylibrary.com/rawls/ retrieved December 312017.

[22] https://www.and.org.au/pages/disability-statistics.html retrieved December 4, 2017.

[23] Huhtanen, S. L. (2013). Allowing Families to be Families. EP Magazine.

[24] Kagan, D. M. (1992). Implications of research on teacher belief. Educational Psychologist 27, 65-90.

[25] Lippman (1972).UNESCO Braille Courier.

[26] Lopez, K. (2013). Socio-cultural Perspectives of Latino Children with Autism and their Families. Dissertation, University of Michigan.

[27] Lynch, E.W., \& Hanson, M.J. (2004). Developing cross-cultural competence. Baltimore, MD: Paul H. Brookes Publishing Company.

[28] Munyi, C. W. (2012). Past and Present Perceptions towards Disability: A Historical Perspective. 32(2).

[29] National Council of Special Education. (2013). Supporting Students with Special Educational Needs in Schools. Co. Meath. 
[30] Nichols, L.A. and B. Keltner. (2005). Indian family adjustment to children with disabilities. American Indian and Alaska Native Mental Health Research. 12, 22-48.

[31] Oliver, M. (1983). Social work with disabled people. Basingstoke: MacMillans.

[32] Shafritz, Jay M. \& Russell, E.W. Introducing Public Administration 2nd Edition. Addison Wesley Longman Inc. 2000, 400.

[33] Skrtic, T. M. (1991). The special education paradox: equity as the way to excellence. Harvard Educational Review, 61, 148-206.

[34] Su, R., Bramwell, B., \&Whalley, P. A. (2018). Cultural Political Economy and Urban Heritage Tourism. Annals of Tourism Research, 68(2018) 30-40.

[35] Watts, R. (2003). Politeness. Cambridge: Cambridge University Press.

[36] World Health Organisation (2011). World Report on Disability. Malta: WHO.

[37] Wright, B.A. (1973). Changes and attitudes towards handicapped people. Rehabilitation Literature, 34, 354368.

[38] Yin, R. K. (2009). Case study research: design and methods (4th ed.). Los Angeles, Calif: Sage Publications. 